\title{
Stereotactic body radiotherapy (SBRT) for oligo-metastatic liver metastases from breast cancer, as an effective and safe alternative to surgery: a review
}

\author{
Shuri Aoki, Hideomi Yamashita, Osamu Abe, Keiichi Nakagawa \\ Department of Radiology, University of Tokyo Hospital, Tokyo, Japan \\ Contributions: (I) Conception and design: S Aoki; (II) Administrative support: H Yamashita, O Abe, K Nakagawa; (III) Provision of study materials or \\ patients: S Aoki; (IV) Collection and assembly of data: S Aoki, H Yamashita; (V) Data analysis and interpretation: S Aoki, O Abe, K Nakagawa; (VI) \\ Manuscript writing: All authors; (VII) Final approval of manuscript: All authors. \\ Correspondence to: Dr. Shuri Aoki. Department of Radiology, University of Tokyo Hospital, Tokyo, 3-7-1 Hongo, Bunkyo-ku, Tokyo 113-8655, Japan. \\ Email: daisyshuri@yahoo.co.jp.
}

\begin{abstract}
The liver is a common organ of metastases from most solid malignancies, including breast cancer, and breast cancer with liver metastases (BCLM) has a poor prognosis despite advances in systemic therapies. It has become widely recognized that local treatments for oligometastases with curative intent could improve disease control and survival outcomes under certain conditions. Regarding local therapy for BCLM, surgical resection had been the first choice though its indications were quite limited. Recently, an increasing number of prospective trials on stereotactic body radiation therapy (SBRT) for liver metastases (LMs) were published, reporting excellent tumor control with less toxicity. According to these reports, breast cancer origin is a favorable prognostic factor in SBRT for liver metastasis. Further research on patient selection and optimal dose fractionation will establish SBRT as a safe and feasible alternative treatment for resection and ablation in selected patients with BCLM. This review intends to provide evidence on the background and methods of focal radiation therapy for LMs, especially BCLM, and describes the current and future role of SBRT in the treatment of BCLM.
\end{abstract}

Keywords: Breast cancer; liver metastases (LM); local control (LC); oligometastases; stereotactic body radiotherapy

Submitted Apr 15, 2020. Accepted for publication May 28, 2020.

doi: $10.21037 /$ tcr-20-1833

View this article at: http://dx.doi.org/10.21037/tcr-20-1833

\section{Liver metastases (LMs) of breast cancer}

The liver is a common organ of metastases from most solid malignancies, including breast cancer. LM develop in approximately $50 \%$ of all patients with metastatic breast cancer, and $5-12 \%$ of patients develop LM as the primary site of breast cancer recurrence (1-5). Breast cancer with LM (BCLM) has a poor prognosis of 4-8 months if left untreated, and 18-24 months even with systemic therapies $(1,2,6)$.

\section{Loco-regional treatment for metastatic breast cancer}

Systemic hormone- and/or chemotherapy (with or without using local treatment modalities) given with palliative intent had been the only available therapy for the vast majority of patients with advanced breast cancer (4,7-9).

Recently, it has become widely recognized that local treatments for oligometastases with curative intent could improve disease control and survival outcomes under 
certain conditions $(5,10-14)$.

Surgical resection has become the first choice offering long-term survival to the patients with limited number of LMs from various primary organs. And patients underwent radical resection have reported 5 -year survivals of 30 $58 \%(15-17)$.

However, resection is possible only in $10-30 \%$ of the cases with LM because of medically and technically reasons, such as number and location of tumors (18-20).

In an effort to provide treatments for patients who are not candidates for surgery, the other local ablative techniques such as radiofrequency ablation (RFA), trancecatheter arterial chemoembolization (TACE), cryotherapy, radioembolization (Y90), thermal ablation, and radiotherapy (RT) are being tried (21-33).

Among them, RFA has been the most widely used ablative technique. However, there are several limitations of RFA application in regard to lesion's location and size $(\leq 3 \mathrm{~cm})$, proximity to great vessels, or subcapsular position as in surgery. In addition, local recurrence after RFA is relatively high and has been reported in up to $40 \%$ of patients especially if located close to the liver hilum $(23,24,31,34)$.

\section{Stereotactic body radiation therapy (SBRT) for LMs}

Previously, the role of RT for liver tumors had been limited due to the high radiation sensitivity of the organ, and it was thought to be difficult to achieve the radiation doses necessary to eradicate metastatic tumors (35).

However, technological advances have made it possible to deliver a very conformal radiation dose to the tumor and a minimal radiation dose to surrounding liver tissues, which allows normal liver tissues to be spared. This technique is known as SBRT, which refers to an ablative RT that focuses high-dose on the tumor in single or several fractions (1 to 6 fractions), in contrast to conventional RT which use low dose per irradiation (usually 1.5-3 Gy) to a larger volume (36-39).

Recently, SBRT has become recognized as non-invasive but curative treatment option for patients with liver oligometastases who are not eligible for other radical treatments; such as surgery, RFA, or liver transplantation.

And an increasing number of prospective and retrospective trials on liver SBRT were published, with encouraging results in terms of local control (LC), toxicity and overall survival (OS), though only a few focusing on SBRT for LMs from breast cancer alone $(13,14,23,32,36-39)$.

\section{Indications for SBRT for LMs eligibility criteria}

Because SBRT is less constrained by the location of liver tumors than surgery, most SBRT trials have defined their treatment as an alternative therapy or a salvage therapy for inoperable or postoperative isolated LMs (40-43).

The patient selection criteria, and optimal dose fractionation for liver SBRT are still under investigation, leading a significant heterogeneity to the backgrounds in the available literature. The most frequently used indications of SBRT for LM are $\leq 5 \mathrm{LMs}$ with maximum tumor sizes of $6 \mathrm{~cm}$, controlled or absent extra-hepatic disease, good performance status (Eastern Cooperative Oncology Group $0-1$ or Karnosky $>70$ ), and adequate hepatic volume and function $(28,38,41-47)$.

Liver function has also been defined in various ways, including adequate baseline hepatic function and ability to spare a critical hepatic volume. Scorsetti et al. (41) showed the patient's treatment algorithm, and they used Child-Pugh score $(\mathrm{A} / \mathrm{B} / \mathrm{C})$ and "free liver volume" $(>1,000 /<1,000 \mathrm{~mL}$ and $\geq 700 /<700 \mathrm{~mL}$ ) as indicators of liver function to separate patient's suitability for SBRT. Of course, Child class $\mathrm{A}$ and $>1,000 \mathrm{~mL}$ were recommend as good indications for liver SBRT.

To prevent adverse events (AEs), the authors have also referred to the other organs at risk (OARs) in their criteria to have distance of $>8 \mathrm{~mm}$ from the targets (41). Age has not been included to selection criterions in almost all studies. Indeed, it is one of the reasons why SBRT has been selected for elderly patients, who are often unsuitable for surgery.

\section{Treatment procedure}

Liver SBRT is technically challenging due to respirationrelated organ motion, requiring highly precise dose planning and delivery, with multiple beams using either coplanar or non-coplanar geometries. Intensitymodulated RT (IMRT), and more recently volume arc radiation therapy (VMAT) and frameless robotic system for radiosurgery (Cyber-Knife ${ }^{\circledR}$ ) have achieved a dose distribution that fits the unevenness of the target, reducing OAR exposure $(14,28,44,48,49)$.

The following processes should be added to treatment planning to address respiratory movements $(28,48-52)$.

* Planning computed tomography (CT) scans should be obtained, at least, above and below the region of interest in expiration and inspiration in addition to 
free breathing. Recently, it has become recommended that simulations using four-dimensional CT (4DCT) be performed to more accurately characterize tumor movement for target delineation.

* Particularly in liver SBRT, which is a solid organ, it is required to fuse magnetic resonance imaging (MRI), and/or 18-fluorodeoxyglucose positron emission tomography (FDG-PET)-CT with contrastenhanced CT.

* Image guided radiation therapy (IGRT) should be performed before each daily session to reduce setup uncertainties. Fiducial markers are employed for target localization in selected patients.

The techniques to reduce respiratory movement itself include oxygen inhalation, abdominal compression, and respiratory arrest (restriction). And in combination with them, as techniques to reduce the influence of respiratory movement, there are the respiratory synchronization and the moving-body tracking $(28,44,48-50)$.

The way of CT imaging and target contouring for treatment planning differs depending on the type of measures for respiratory movement, so it is important to devise an optimal protocol for each facility. Practice guidelines for the performance of SBRT were published in 2010 by ASTRO and ACR (53).

\section{Dose prescription}

No standard criteria for prescription dose and fraction have not been established for SBRT of LM, with few large-scale reports and no randomized phase III data. Furthermore, the appropriate regimen would vary depending on the size and location of the tumor and its relationship with OARs, so the prescription for fractionated SBRT will vary between studies, ranging from 25 to 75 Gy in 3 to 6 fractions, most commonly 3 fractions $(44,46,54,55)$. For 3 fractions regimen of SBRT, Chang et al. (56) recommended to use a total dose of $\geq 48$ Gy to obtain sufficient LC (1-year LC; $>90 \%)$. For single fraction SBRT, there are several prospective trial reports, prescribing 14-30 Gy $(57,58)$. We reviewed studies on SBRT of LMs including breast cancer (Table 1), with regard to number of patients/number of lesions, number of cases from breast cancer, dose prescription, toxicity and outcome, in terms of LC and OS. Many reports so far have not changed the dose prescription depending on the primary organ or pathology. However, in the future, it might be individualized as the difference in radiation sensitivity and interaction with combination therapy become clear.

\section{Dose constrains}

Some previously published papers have shown restrictions on the dose of OAR in liver SBRT. Scorsetti et al. (62). described the recommended dose constraints for OAR as shown in Table 2. For example, healthy liver volume (excluding cumulative GTV) receiving less than 15 Gy should be at least $700 \mathrm{~cm}^{3}$. V21Gy (percentage of the volume of an organ receiving $21 \mathrm{~Gy}$ ) for the duodenum, small bowel, esophagus, and stomach should be less than $1 \%$. The maximum dose delivered to $0.1 \mathrm{~cm}$ of the target volume (D $0.1 \mathrm{~cm}^{3}$ ) for the spinal cord was limited to less than 18 Gy. There have been several reports of clinical trials performed on slightly different criteria, which can be very helpful $(44,47,55,63)$.

\section{Concomitant therapy}

Prolonged prognosis could be expected by adding SBRT to systemic therapy (55).

The sequence and timing of RT and systemic therapy for oligo BCLM patients is still being discussed, but no studies have reported increased AEs with combination of systemic therapy and SBRT $(60,62)$.

\section{Treatment results of SBRT for LM}

An increasing number of retrospective and prospective studies have demonstrated the efficacy of SBRT for multiprimary LM including breast cancer.

In general, excellent LC of LM treated by SBRT has been reported. LC rates range from $70 \%$ to $100 \%$ at 1 year and from $60 \%$ to $90 \%$ at 2 years (Table 1$)(28,47,59,63)$.

In addition, improved LC after liver SBRT would prolong their OS. Median OS after SBRT for LM varied in the wide range from 10 to 48 months $(28,38,47,52,63)$. The differences between published studies is thought to be dependent on the tumor volume and histopathology, prior therapy, RT dose, and fractionation regimens that have been used, and so on.

Some reports of multi-primary LM have indicated breast cancer origin as a good prognostic factor $(47,55,58,61,64)$. Rusthoven et al. (47) and Mahadevan et al. (61) classified the primary tumor of LM into two groups with favorable 
Table 1 Results of current studies on SBRT for liver metastases (including breast cancer origin)

\begin{tabular}{|c|c|c|c|c|c|c|c|c|c|c|}
\hline Reference & $\begin{array}{l}\text { Study } \\
\text { year }\end{array}$ & $\begin{array}{l}\text { Number } \\
\text { of patients } \\
\text { [lesions] }\end{array}$ & $\begin{array}{c}\text { BCLM } \\
\text { patients }\end{array}$ & $\begin{array}{l}\text { Tumor volume } \\
\text { (median, } \mathrm{cm}^{3} \text { ) }\end{array}$ & $\begin{array}{l}\text { Follow up } \\
\text { (median, } \\
\text { months) }\end{array}$ & $\begin{array}{l}\text { RT dose } \\
\text { (Gy/Fr) }\end{array}$ & $\begin{array}{c}\text { Toxicity } \\
\text { (Grade } 3 / \geq 4 \text { ) }\end{array}$ & \multicolumn{2}{|c|}{ Survival } & $\begin{array}{c}\text { Local } \\
\text { control (\% or } \\
\text { median) }\end{array}$ \\
\hline $\begin{array}{l}\text { Lee et al. } \\
\text { (52) }\end{array}$ & 2009 & 68 [143] & 12 & 75.9 & 10.8 & $\begin{array}{l}41.4 \text { (27.7- } \\
60) \text { Gy/6 Fr }\end{array}$ & $\begin{array}{c}\text { Acute: } 6 \\
(9 \%) / 1(1 \%), \\
\text { late: } 0 / 0\end{array}$ & 17.6 & 79 (1 y) & $71(1 \mathrm{y})$ \\
\hline $\begin{array}{l}\text { Rusthoven } \\
\text { (47) }\end{array}$ & 2009 & 48 [63] & & $\begin{array}{c}\text { NA (diameter } \\
2.7 \mathrm{~cm} \text { ) }\end{array}$ & 16 & $36-60 \mathrm{~Gy} / 3 \mathrm{Fr}$ & G3 $1(2 \%)$ & 20.5 & & $\begin{array}{c}92 / 95 \\
(1 \mathrm{y} / 2 \mathrm{y})\end{array}$ \\
\hline $\begin{array}{l}\text { Fumagalli } \\
\text { et al. (54) }\end{array}$ & 2012 & 90 [139] & 8 & 28 & 17 & $\begin{array}{c}27-60 \mathrm{~Gy} / \\
3-6 \mathrm{Fr}\end{array}$ & $0 / 0$ & & 70.0 (2 y) & $\begin{array}{c}84.5 / 66.1 \\
(1 \mathrm{y} / 2 \mathrm{y})\end{array}$ \\
\hline $\begin{array}{l}\text { Scorsetti } \\
\text { et al. (55) }\end{array}$ & 2016 & $33[43]$ & $33(100 \%)$ & 20 & 24 & $\begin{array}{c}\text { 48-57 Gy/ } \\
\text { 3-4 Fr }\end{array}$ & $0 / 0$ & 48 & $\begin{array}{c}93 / 66 \\
(1 \mathrm{y} / 2 \mathrm{y})\end{array}$ & $\begin{array}{c}98 / 90 \\
(1 \mathrm{y} / 2 \mathrm{y})\end{array}$ \\
\hline $\begin{array}{l}\text { Onal et al. } \\
(60)\end{array}$ & 2018 & 22 [29] & $22(100 \%)$ & & 16 & $54 \mathrm{~Gy} / 3 \mathrm{Fr}$ & NA/O & & $\begin{array}{c}85 / 57 \\
(1 \mathrm{y} / 2 \mathrm{y})\end{array}$ & $\begin{array}{c}100 / 88 \\
(1 \mathrm{y} / 2 \mathrm{y})\end{array}$ \\
\hline $\begin{array}{l}\text { Mahadevan } \\
\text { et al. (61) }\end{array}$ & 2018 & 427 [568] & 42 & 40 & 14 & $\begin{array}{c}45 \text { [12- } \\
\text { 60] Gy/3 Fr }\end{array}$ & $0 / 0$ & 22 & & $\begin{array}{l}52 \text { months } \\
\text { (median) }\end{array}$ \\
\hline
\end{tabular}

SBRT, stereotactic body radiation therapy; BCLM, breast cancer liver metastases; Gy, gray; Fr, fractions; NA, non applicable; y, years.

Table 2 Protocol dose constrains [dose constraints for organ at risks (OARs)]

\begin{tabular}{|c|c|c|}
\hline Organ & Dose-volume limits & Other conditions \\
\hline Healthy liver (<15 Gy) & $>700 \mathrm{cc}$ & $\begin{array}{c}\text { Healthy liver } \\
\text { volume }>700 \mathrm{cc}\end{array}$ \\
\hline Spinal cord & D $0.1 \mathrm{~cm}^{3}<18 \mathrm{~Gy}$ & \\
\hline Kidneys $(R+L)$ & V15 Gy <35\% & \\
\hline $\begin{array}{l}\text { Stomach, duodenum, } \\
\text { small bowel }\end{array}$ & V21 Gy <1\% & $\begin{array}{c}\text { GTV }>8 \mathrm{~mm} \text { from } \\
\text { the OARs }\end{array}$ \\
\hline Heart & V30 Gy <1\% & \\
\hline Ribs & D30 $\mathrm{cm}^{3}<30$ Gy & \\
\hline
\end{tabular}

OAR, organ at risk; Gy, gray; D $0.1 \mathrm{~cm}^{3} / 30 \mathrm{~cm}^{3}$, the maximum dose delivered to $0.1 \mathrm{~cm}$ of the target volume; V15/21/30 Gy, percentage of the volume of an organ receiving 15, 21, $30 \mathrm{~Gy}$; GTV, gross tumor volume.

and unfavorable based on survival and classify breast cancer with favorable. In addition, Swaminath et al. (64) reported, from their data of 81 patients with 142 metastases received liver SBRT, breast cancer subtype was one of the factors influencing the time to local progression.

Though only a few studies focused on BCLM alone, Onal et al. (60) combined liver SBRT and systemic treatment in 22 patients with 29 BCLM and reported excellent result (median follow-up time of 16.0 months); 1 and 2-year OS rates $85 \%$ and $57 \%$, and the 1 - and 2-year LC rates $100 \%$ and $88 \%$, respectively. Scorsetti et al. (62) had treated lung or liver oligometastases from breast cancer with SBRT and achieved 1- and 2-year OS rates $93 \%$ and $66 \%$, and the 1- and 2-year actuarial LC rates $100 \%$ and $88 \%$, respectively. The authors of these studies concluded that SBRT may be an effective and safe treatment option in selected patients with BCLM. Chang et al. (56) confirmed the better LC for lesion treated with higher prescription dose and suggested the use of a total dose $>48$ Gy for a 3 fractions regimen of SBRT.

\section{Predictors}

Various factors have been reported to be prognostic factors 
associated with the effectiveness of liver SBRT. Favorable predictors of LC mentioned in most publications are tumor size, prescription dose, and histology (47,49,55,59-61). And as additional factors related favorable OS, performance status, solitary metastasis, metachronous metastases, and pre-SBRT chemotherapy etc. have been reported (43).

Regarding tumor size, diameter of 30 or $40 \mathrm{~mm}$ is frequently used as cut-off value. Yamashita et al. (49) reported the maximum tumor diameter $>30 \mathrm{vs} . \leq 30 \mathrm{~mm}$ had been the only significant factor for LCR. Mahadevan et al. (61) reported the results after SBRT of a total of 427 patients with LM from different origin including 42 BCLM patients and claimed smaller tumor volumes $\left(<40 \mathrm{~cm}^{3}\right)$ are associated with improved LC and OS.

Prescription dose is also an important prognostic factor. Numerous studies on liver SBRT confirmed the correlation between dose prescription and LC. Chang et al. (56) reported that total dose $(\mathrm{P}=0.0015)$, dose/fraction $(\mathrm{P}=0.003)$, and BED $(\mathrm{P}=0.004)$ all correlated with $\mathrm{LC}$ in their retrospective study. Mahadevan et al. (61) and Yuan et al. (44) mentioned above, mentioned $\mathrm{BED}_{10} \geq 100 \mathrm{~Gy}$ was also associated with improved LC (two-year LC rates; $77.2 \%$ vs. 59.6\%). McCammon et al. (65) demonstrated significant improvement in LC with increasing dose, with the 3 -year LC rate in their series $89.3 \%, 59 \%$ and $8.1 \%$ for those lesions that received 54-60 Gy, 36-53.9 Gy and less than $36 \mathrm{~Gy}$, respectively $(\mathrm{P}<0.01)$. Though most reports have not changed the prescribed dose depending on the pathology or primary lesion, Yamashita et al. (49) proposed that increasing the dose to metastatic liver tumors appeared to be reasonable since metastatic lung tumors require dose escalation due to relatively low radio-sensitivity.

\section{Toxicity}

Severe toxicity associated with liver radiation therapy is rare, especially in hepatic SBRT. Ihnát et al. (28) have stated grade 3 side effects would occur in less than $5 \%$ of SBRT cases.

First, talking about acute AEs, grade 1-2 gastrointestinal toxicity (nausea, vomiting, abdominal pain, and peptic ulcers) are the most frequent AEs, which are experienced amongst $10-30 \%$ of patients (38). And less frequently, depending on the treatment site, chest wall pain, dermatitis, pneumonia, dermatitis, renal dysfunction, etc., could occur.

Radiation-induced liver disease (RILD) is an acute reaction occurring between 2 weeks and 4 months after RT in patients who have received a certain dose to the liver. It is characterized by anicteric ascites with elevation of alkaline phosphatase and liver transaminases and could result in liver failure and death $(66,67)$.

Emami et al. (68) had reported doses at $5 \%$ risk of RILD as 50, 35 and $30 \mathrm{~Gy}$, for $1 / 3,2 / 3$, and the whole liver, respectively. Although this criterion is still widely used, Lawrence et al. (69) later stated that with proper restriction of the irradiated area of normal liver, it was possible to administer more than 90 Gy without occurring RILD. Dawson (70) have shown, from 204 patient data, the dose at $5 \%$ risk of RILD was 54 and 100 Gy when $2 / 3$ and $1 / 3$ of the liver was irradiated, which was higher than previous reports. From the above, though RILD is the most limiting $\mathrm{AE}$ of liver irradiation, its occurrence depends on the volume of the irradiated liver, so it can be prevented by reducing the dose to the normal liver tissue.

After a report by Méndez Romero et al. (71) referring to two cases of RILD after SBRT, few cases of RILS have been described in the studies focused on SBRT of LMs. The recent very low incidence of RILD is probably the consequence of extreme accuracy of radiation delivery on target during SBRT.

Late AEs include gastrointestinal ulcers and perforations, bile duct stenosis, pulmonary fibrosis, renal fibrosis, etc., but serious cases about all of which have been rarely reported.

\section{Conclusions}

The data from published reports on SBRT for liver oligometastases have shown promising results especially in terms of LC and safety, despite most patients had been determined to be inoperable before treatment. It might be said that SBRT is a safe and feasible alternative treatment to resection and ablation in selected patients with BCLM.

However, the number of cases and observation period of these previous reports are insufficient, and the patient selection criteria and optimal dose and fractionation for liver SBRT are still under investigation. Prospective randomized trials and further studies are required to define appropriate targets and methods for SBRT and establish a role in BCLM.

\section{Acknowledgments}

Funding: None. 


\section{Footnote}

Provenance and Peer Review: This article was commissioned by the Guest Editors (Tadahiko Shien and Kaori Terata) for the series "Loco-regional therapy for metastatic breast cancer" published in Translational Cancer Research. The article was sent for external peer review organized by the Guest Editors and the editorial office.

Conflicts of Interest: All authors have completed the ICMJE uniform disclosure form (available at http://dx.doi. org/10.21037/tcr-20-1833). The series "Loco-regional therapy for metastatic breast cancer" was commissioned by the editorial office without any funding or sponsorship. The authors have no other conflicts of interest to declare.

Ethical Statement: The authors are accountable for all aspects of the work in ensuring that questions related to the accuracy or integrity of any part of the work are appropriately investigated and resolved.

Open Access Statement: This is an Open Access article distributed in accordance with the Creative Commons Attribution-NonCommercial-NoDerivs 4.0 International License (CC BY-NC-ND 4.0), which permits the noncommercial replication and distribution of the article with the strict proviso that no changes or edits are made and the original work is properly cited (including links to both the formal publication through the relevant DOI and the license). See: https://creativecommons.org/licenses/by-nc-nd/4.0/.

\section{References}

1. Hoe AL, Royle GT, Taylor I. Breast liver metastases: incidence, diagnosis and outcome. J R Soc Med 1991;84:714-6.

2. Insa A, Lluch A, Prosper F, et al. Prognostic factors predicting survival from first recurrence in patients with metastatic breast cancer: analysis of 439 patients. Breast Cancer Res Treat 1999;56:67-78.

3. Elias D, Maisonnette F, Druet-Cabanac M, et al. An attempt to clarify indications for hepatectomy for liver metastases from breast cancer. Am J Surg 2003;185:158-64.

4. Adam R, Aloia T, Krissat J, et al. Is Liver Resection Justified for Patients With Hepatic Metastases From Breast Cancer? Ann Surg 2006;244:897-907; discussion
907-8.

5. He ZY, Wu S, Peng F, et al. Up-Regulation of RFC3 Promotes Triple Negative Breast Cancer Metastasis and is Associated with Poor Prognosis Via EMT. Transl Oncol 2017;10:1-9.

6. Eng LG, Dawood S, Sopik V, et al. Ten-year survival in women with primary stage IV breast cancer. Breast Cancer Res Treat 2016;160:145-52.

7. Harbeck N, Gnant M. Breast cancer. Lancet 2017;389:1134-50.

8. Largillier R, Ferrero JM, Doyen J, et al. Prognostic factors in 1,038 women with metastatic breast cancer. Ann Oncol 2008;19:2012-9.

9. Gerratana L, Fanotto V, Bonotto M, et al. Pattern of metastasis and outcome in patients with breast cancer. Clin Exp Metastasis 2015;32:125-33.

10. Hellman S, Weichselbaum RR. Oligometastases. J Clin Oncol 1995;13:8-10.

11. Niibe Y, Hayakawa K. Oligometastases and oligorecurrence: the new era of cancer therapy. Jpn J Clin Oncol 2010;40:107-11.

12. Niibe $Y$, Nishimura T, Inoue $T$, et al. Oligo-recurrence predicts favorable prognosis of brain-only oligometastases in patients with non-small cell lung cancer treated with stereotactic radiosurgery or stereotactic radiotherapy: a multi-institutional study of 61 subjects. BMC Cancer 2016;16:659.

13. Onishi H, Ozaki M, Kuriyama K, et al. Stereotactic body radiotherapy for metachronous multisite oligo-recurrence: a long-surviving case with sequential oligo-recurrence in four different organs treated using locally radical radiotherapy and a review of the literature. Pulm Med 2012;2012:713073.

14. Aoki S, Yamashita H, Takahashi W, et al. Salvage stereotactic body radiotherapy for post-operative oligo-recurrence of non-small cell lung cancer: A single-institution analysis of 59 patients. Oncol Lett 2020;19:2695-704.

15. Lemke J, Cammerer G, Ganser J, et al. Survival and prognostic factors of colorectal liver metastases after surgical and nonsurgical treatment. Clin Colorectal Cancer 2016;15:e183-e192.

16. Kanas GP, Taylor A, Primrose JN, et al. Survival after liver resection in metastatic colorectal cancer: review and meta-analysis of prognostic factors. Clin Epidemiol $2012 ; 4: 283-301$. 
17. Sadot E, Lee SY, Sofocleous CT, et al. Hepatic resection or ablation for isolated breast cancer liver metastasis: A case-control study with comparison to medically treated patients. Ann Surg 2016;264: 147-54.

18. Scheele J, Stangl R, Altendorf-Hofmann A. Hepatic metastases from colorectal carcinoma: impact of surgical resection on the natural history. Br J Surg 1990;77:1241-6.

19. Khan K, Wale A, Brown G, et al. Colorectal cancer with liver metastases: neoadjuvant chemotherapy, surgical resection first of palliation alone? World J Gastroenterol 2014;20:12391-406.

20. Grundmann RT. Current state of surgical treatment of liver metastases from colorectal cancer. World J Gastrointest Surg 2011;3:183-196.

21. Ihnát $P$, Vávra $P, Z$ Zonča P. Treatment strategies for colorectal carcinoma with synchronous liver metastases: which way to go? World J Gastroenterol 2015;21:7014-21.

22. Bale R, Putzer D, Schullian P. et al. Local Treatment of Breast Cancer Liver Metastasis. Cancers (Basel) 2019;11:1341.

23. Cacciola A, Parisi S, Tamburella C, et al. Stereotactic body radiation therapy and radiofrequency ablation for the treatment of liver metastases: How and when? Rep Pract Oncol Radiother 2020;25:299-306.

24. Xi XJ, Zhang Y, Yin YH, et al. Bronchobiliary fistula following radiofrequency ablation for liver metastases from breast cancer: A case report and literature review. Medicine (Baltimore) 2018;97:e12760.

25. Kiszkaą J, Karczmarek-Borowska B. Radioembolization treatment for liver metastases. Contemp Oncol (Pozn) 2017;21:274-8.

26. Eichler K, Jakobi S, Gruber-Rouh T, et al. Transarterial chemoembolisation (TACE) with gemcitabine: phase II study in patients with liver metastases of breast cancer. Eur J Radiol 2013;82:e816-22.

27. Vogl TJ, Naguib NN, Nour-Eldin NE, et al. Transarterial chemoembolization (TACE) with mitomycin $\mathrm{C}$ and gemcitabine for liver metastases in breast cancer. Eur Radiol 2010;20:173-80.

28. Ihnát $\mathrm{P}, \mathrm{Skácelíková} \mathrm{E}$, Tesař $\mathrm{M}$, et al. Stereotactic body radiotherapy using the CyberKnife ${ }^{\circledR}$ system in the treatment of patients with liver metastases: state of the art. Onco Targets Ther 2018;11:4685-91.

29. Saxena A, Kapoor J, Meteling B, et al. Yttrium-90 radioembolization for unresectable, chemoresistant breast cancer liver metastases: a large single-center experience of
40 patients. Ann Surg Oncol 2014;21:1296-303.

30. Vogl TJ, Farshid P, Naguib NN, et al. Thermal ablation therapies in patients with breast cancer liver metastases: a review. Eur Radiol 2013;23:797-804.

31. Bai XM, Yang W, Zhang ZY, et al. Long-term outcomes and prognostic analysis of percutaneous radiofrequency ablation in liver metastasis from breast cancer. Int J Hyperthermia 2019;35:183-93.

32. de Vin T, Engels B, Gevaert T. Stereotactic radiotherapy for oligometastatic cancer: a prognostic model for survival. Ann Oncol 2014;25:467-71.

33. Garrean S, Hering J, Saied A, et al. Radiofrequency ablation of primary and metastatic liver tumors: a critical review of the literature. Am J Surg 2008;195:508-20.

34. Livraghi T, Solbiati L, Meloni F, et al. Percutaneous radiofrequency ablation of liver metastases in potential candidates for resection: the "test-of-time approach." Cancer 2003;97:3027-35.

35. Withers HR, Taylor JM, Maciejewski B. Treatment volume and tissue tolerance. Int J Radiat Oncol Biol Phys 1988;14:751-9.

36. Blomgren H, Lax I, Naslund I, et al. Stereotactic high dose fraction radiation therapy of extracranial tumors using an accelerator. Clinical experience of the first thirty-one patients. Acta Oncol 1995;34:861-70.

37. Tree AC, Khoo VS, Eeles RA, et al. Stereotactic body radiotherapy for oligometastases. Lancet Oncol 2013;14:e28-e37.

38. Høyer M, Swaminath A, Bydder S, et al. Radiotherapy for liver metastases: a review of evidence. Int J Radiat Oncol Biol Phys 2012;82:1047-57.

39. Dieterich S, Gibbs IC. The CyberKnife in clinical use: current roles, future expectations. Front Radiat Ther Oncol 2011;43:181-94.

40. Pan YX, Xi M, Fu YZ, et al. Stereotactic Body Radiotherapy as a Salvage Therapy after Incomplete Radiofrequency Ablation for Hepatocellular Carcinoma: A Retrospective Propensity Score Matching Study. Cancers (Basel) 2019;11:1116.

41. Scorsetti M, Clerici E, Comito T. Stereotactic body radiation therapy for liver metastases. J Gastrointest Oncol 2014;5:190-7.

42. Berkovic P, Gulyban A, Nguyen PV, et al. Stereotactic robotic body radiotherapy for patients with unresectable hepatic oligorecurrence. Clin Colorectal Cancer 2017;16:349-357.e1. 
43. Fode MM, Høyer M. Survival and prognostic factors in 321 patients treated with stereotactic body radiotherapy for oligo-metastases. Radiother Oncol 2015;114:155-60.

44. Yuan ZY, Meng MB, Liu CL, et al. Stereotactic body radiation therapy using the CyberKnife(®) system for patients with liver metastases. Onco Targets Ther 2014;7:915-23.

45. Kress MS, Collins BT, Collins SP, et al. Stereotactic body radiation therapy for liver metastases from colorectal cancer: analysis of safety, feasibility, and early outcomes. Front Oncol 2012;2:8.

46. Rule W, Timmerman R, Tong L, et al. Phase I doseescalation study of stereotactic body radiotherapy in patients with hepatic metastases. Ann Surg Oncol 2011;18:1081-7.

47. Rusthoven KE, Kavanagh BD, Cardenes H, et al. Multiinstitutional phase I/II trial of stereotactic body radiation therapy for liver metastases. J Clin Oncol 2009;27:1572-8.

48. Yamashita H, Takahashi W, Haga A, et al. Stereotactic body radiotherapy for small lung tumors in the university of Tokyo hospital. Biomed Res Int 2014;2014:136513.

49. Yamashita H, Onishi H, Matsumoto Y, et al. Local effect of stereotactic body radiotherapy for primary and metastatic liver tumors in 130 Japanese patients. Radiat Oncol 2014;9:112.

50. Aoki S, Yamashita H, Haga A, et al. Flattening filter-free technique in volumetric modulated arc therapy for lung stereotactic body radiotherapy: A clinical comparison with the flattening filter technique. Oncol Lett 2018;15:3928-36.

51. Ambrosino G, Polistina F, Costantin G, et al. Imageguided robotic stereotactic radiosurgery for unresectable liver metastases: Preliminary results. Anticancer Res 2009;29:3381-4.

52. Lee MT, Kim JJ, Dinniwell R, et al. Phase I study of individualized stereotactic body radiotherapy of liver metastases. J Clin Oncol 2009;27:1585-91.

53. Potters L, Kavanagh B, Galvin JM, et al. American Society for Therapeutic Radiology and Oncology (ASTRO) and American College of Radiology (ACR) practice guideline for the performance of stereotactic body radiation therapy. Int J Radiat Oncol Biol Phys 2010;76:326-32.

54. Fumagalli I, Bibault JE, Dewas S, et al. A single-institution study of stereotactic body radiotherapy for patients with unresectable visceral pulmonary or hepatic oligometastases. Radiat Oncol 2012;7:164.

55. Scorsetti M, Franceschini D, De Rose F, et al. Stereotactic body radiation therapy: A promising chance for oligometastatic breast cancer. Breast 2016;26:11-7.

56. Chang DT, Swaminath A, Kozak M, et al. Stereotactic body radiotherapy for colorectal liver metastases: a pooled analysis. Cancer 2011;117:4060-9.

57. Goodman KA, Wiegner EA, Maturen KE, et al. Doseescalation study of single-fraction stereotactic body radiotherapy for liver malignancies. Int J Radiat Oncol Biol Phys 2010;78:486-93.

58. Herfarth KK, Debus J, Lohr F, et al. Stereotactic singledose radiation therapy of liver tumors: results of a phase I/ II trial. J Clin Oncol 2001;19:164-70.

59. Wulf J, Guckenberger M, Haedinger U, et al. Stereotactic radiotherapy of primary liver cancer and hepatic metastases. Acta Oncol 2006;45:838-47.

60. Onal C, Guler OC, Yildirim BA. Treatment outcomes of breast cancer liver metastasis treated with stereotactic body radiotherapy. Breast 2018;42:150-6.

61. Mahadevan A, Blanck O, Lanciano R, et al. Stereotactic Body Radiotherapy (SBRT) for liver metastasis - clinical outcomes from the international multi-institutional RSSearch® Patient Registry. Radiat Oncol 2018;13:26.

62. Scorsetti M, Franceschini D, De Rose F, et al. The role of SBRT in oligometastatic patients with liver metastases from breast cancer. Rep Pract Oncol Radiother 2017;22:163-9.

63. Scorsetti M, Comito T, Clerici E, et al. Phase II trial on SBRT for unresectable liver metastases: long-term outcome and prognostic factors of survival after 5 years of follow-up. Radiat Oncol 2018;13:234.

64. Swaminath A, Massey C, Brierley JD, et al. Accumulated Delivered Dose Response of Stereotactic Body Radiation Therapy for Liver Metastases. Int J Radiat Oncol Biol Phys 2015;93:639-48.

65. McCammon R, Schefter TE, Gaspar LE, et al. Observation of a dose-control relationship for lung and liver tumors after stereotactic body radiation therapy. Int J Radiat Oncol Biol Phys 2009;73:112-8.

66. Hoyer M, Roed H, Traberg Hansen A, et al. Phase II study on stereotactic body radiotherapy of colorectal metastases. Acta Oncol 2006;45:823-30.

67. Koay EJ, Owen D, Das P. Radiation-induced liver disease and modern radiotherapy. Semin Radiat Oncol 2018;28:321-31.

68. Emami B, Lyman J, Brown A, et al. Tolerance of normal tissue to therapeutic irradiation. Int J Radiat Oncol Biol Phys 1991;21:109-22.

69. Lawrence TS, Ten Haken RK, Kessler ML, et al. The use 
of 3- D dose volume analysis to predict radiation hepatitis. Int J Radiat Oncol Biol Phys 1992;23:781-8.

70. Dawson LA, Ten Haken RK, Lawrence TS. Partial irradiation of the liver. Semin Radiat Oncol 2001;11:240-6.
71. Méndez Romero A, Wunderink W, Hussain SM, et al. Stereotactic body radiation therapy for primary and metastatic liver tumors: A single institution phase I-Ii study. Acta Oncol 2006;45:831-7.

Cite this article as: Aoki S, Yamashita $\mathrm{H}$, Abe O, Nakagawa K. Stereotactic body radiotherapy (SBRT) for oligo-metastatic liver metastases from breast cancer, as an effective and safe alternative to surgery: a review. Transl Cancer Res 2020;9(8):50875095. doi: 10.21037/tcr-20-1833 